\title{
E- HRM Practices in the IT Industry with Special Reference to the State of Karnataka
}

\author{
Srihari. S, Subhasree Kar
}

\begin{abstract}
Human resource management is constantly evolving into a technology-based service provider to their employees. In today's organizations, employees see the face of $H R$ as an Intranet portal rather than a human on the other side. This transformation of Human Resource services through technology is now being coined as E-HRM or electronic human resource. The Use of E-HRM in today's Organizations, are in many function areas such as training and development, performance management systems, hiring and employee self-service. Organisations who adopt HR technology tools outperform those that do not. Interestingly early on the HR department was the last recipient of IT benefits in any organization, it started from keeping the database of the employees. In the present scenario employees are considered as the strategic partners of the organization and the use of high-end software have changed the face of HR departments and a new term has been coined as E-HRM. This present paper tries to evaluate the role of E-HRM in IT companies and also to measure the acceptance and effectiveness of the same at the different levels of management.
\end{abstract}

Keywords: E-HRM, Effectiveness, Information Technology.

\section{INTRODUCTION}

The application of Information Technology can be traced back in the mid-70s' when some of the American and British banks started to install the computers and some of the Database related software. The motive was to keep the database of the customers and then at the second stage they start to track the respective transaction of the customer. Gradually this system of keeping the track of customers and their related transaction started to flow in rest of the industries. Then in the decade of $90 \mathrm{~s}$ almost all the industries started to implement the newly available software which are able to perform on the multitasking level and the next level was the introduction of ERP (Enterprise Resource Planning) in the organizations. ERP-1, ERP-2 and other related software which have changed the face of industry forever. In the present scenario of $21^{\text {st }}$ century HRM is one of the most looked upon area for most of the give organization this is because of the reason that the work culture has changed a lot. There was a time when the organization used to hire people and train them according to the requirement of the job but now the companies want skilled and multitasking employees who are able to perform from the day of appointment and in lieu of the same, down the line, the orientation of labor

Revised Manuscript Received on November 11, 2019.

* Correspondence Author

Srihari. S, CMR University, Bangalore - India India. market has also changed a lot which is all ready to cater to the need.

Many of the previous researchers and school of thoughts which were initiated by great thinkers like Peter F. Drucker (1992), Mosely (1997), Kotler(1995) and many others had specially quoted the importance of HR practices in any of the given organization. They had also stated the need and value of established HR department in any of the given organization and the blend of Information Technology will certainly add value to the same. Integration of human skills, basic HR functions with the righteous use of information technology is going to result in the overall development of the organization along with the long-term association of the employees with the respective organization.

HR department is one of the early adopters of Information Technology in terms of procuring hardware and using available database software, all other departments started to understand the benefits and started to find avenues of Information Technology that can benefit their respective departments and in the current scenario this has become the common practice for all the departments of any given organization to implement the latest available software and to upgrade the performance of the respective employees. Hendrickson (2003).

From the starting of $21^{\text {st }}$ century, the term E-HRM was coined and it has now become the talk of the town, it is because of this reason, that in the present scenario most of the strategies are formulated along with some or the other implications of Information Technology at different levels. As far as the HR practices are concerned, recruiting of right person at the right place, providing customized training to employees, implication of organizational policies, following the objectives of the management, etc. can be considered as the core activities and in order to speed up the things or to maintain the competitive edge in present market it is very important to look at implementation of latest IT practices in the said department.

All the MNCs' are making gradual use of latest available web technologies and the related channels, specifically talking about the HR department it is more related to skill development intellectual level and planning of higher order. There is nothing free in the world and the same applies to E-HRM as well, it costs money and a lot of money to the present and forthcoming organizations, on the other hand there is no way to ignore the implication of the same in the given organization. This is because of this reason that the organizations are now shifting from hard work to smart work. This means that the organizations are shifting to strategic HRM, reduction of cost, increasing the productivity, focusing on 


\section{E- HRM Practices in the IT Industry with Special Reference to the State of Karnataka}

quality of work life of the given group of employees, and fixing up of the responsibilities of the employees at all the levels.

\section{IMPORTANCE OF E-HRM}

As discussed above E-HRM is the key to develop the high end profile of the employees on real time basis and improve the work culture in return. Some of the other benefits can be stated as follows:

1. The level of transparency increases if E-HRM is implemented in the department.

2. The respective clientele of the organization i.e. employees and management both are benefitted by the implementation of E-HRM,

3. As stated above the initial investment is high but then again at the second level HR department becomes more cost effective and level of understanding about the organizational goals and objectives also increases.

4. This is a well-known fact that we need humans to manage humans, but then again, the implementation of E-HRM speed's up the things and even the level of accuracy is also increased.

5. It is having a positive impact on the respective productivity of the employees, in the sense that there job profiles are clear and level of hierarchy is also decreased.

6. E-HRM can also be viewed as a system of benchmarking, where the given organization achieves a landmark in recruiting the best available employees and at the second level to retain them for a longer period of time in the same organization.

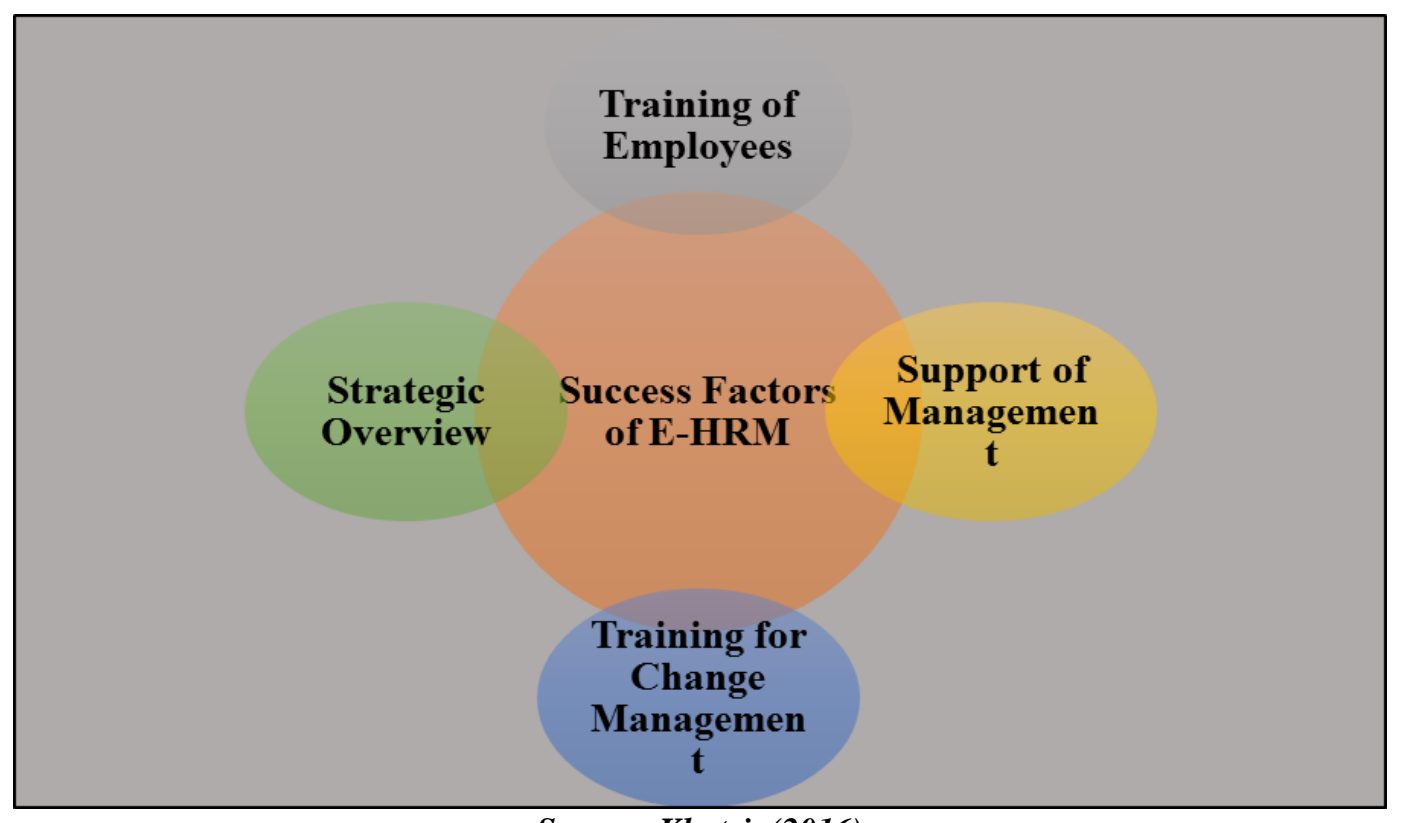

Source: Khatri, (2016)

Figure 1: Factors of E-HRM

\section{LITERATURE REVIEW}

Rangarao and Raju. S (2014) revealed in their study that in the organization effectiveness and efficiency of the human resource management plays a very important role. The meaning of human resource is behavior of employees rather than employee's presence. This study was trying to achieve goals of the organization with the help of electronic human resource management.

Danialari (2013) stated that the focus of E-HRM is not only on the process of information gathering in a given HR environment, but also it is considered as a two way process of sending and receiving feedback to the employees and the respective level of management. This is because of the reason that same type of information at all levels may create monotony, high consumption of time can increase the idle man-hours.

\section{OBJECTIVE OF THE STUDY}

- To study the effectiveness of E-HRM Practices on Hiring, Learning \& Development, Performance Management and Employee self-service System.

- To study the Gaps and inadequacies of the prevailing systems.

- To evaluate the implications of E-HRM Practices on organizational performance.

\section{Hypothesis}

Hypothesis 1

$\mathrm{H}_{0}$ : Demographic and work related factors of the respondents do not act as barrier to the implementation of E-HRM in IT industry.

$\mathrm{H}_{1}$ : Demographic and work related factors of the respondents act as barrier to the implementation of E-HRM in IT industry. 


\section{RESEARCH METHODOLOGY}

\section{Research Instrument and Data Collection}

This present study is based on primary data on the first place. As the topic suggests it is a study of implementing E-HRM in the IT companies working in the province of Karnataka. As a matter of fact, it is already mentioned in the above given matter that in order to achieve success form the implementation of any new initiative in any of the given organization it is necessary that both the employee and employer are working hand in hand for the success of the same. Here in present study as well the researcher has taken the sample from both the levels of management. In order to get the clear glimpse of the variables under study, five different IT related companies are chosen and a sample of 200 employees and 50 managerial level personals are chosen from the same. The bifurcation of the sample is such that 40 respondents from each company and 10 managerial level persons are chosen at random from the same.

In order to collect the primary data, a structured questionnaire was designed and duly exercised with the selected respondents. The general information sought in the questionnaire was related to demographic and job related profile of the respondents. Even the benefits and shortcomings of E-HRM are also discussed. Most of the questions are scale based, where 1 refers to highly agreed and 5 refers to highly disagreed.

\section{Tools of Data Analysis}

The Statistical package tool (SPSS) version 22 was used to analyze the data.

\section{DATA ANALYSIS AND INTERPRETATION}

Hypothesis 1 (Demographic Factors)-Chi Square Test
On the basis of gender

\begin{tabular}{|c|c|c|c|c|}
\hline $\begin{array}{l}\text { Degree of Job } \\
\text { Performance }\end{array}$ & \multicolumn{2}{|c|}{ Gender } & \multirow{2}{*}{ Total } & \multirow{2}{*}{$\begin{array}{c}\text { Value of } \\
\chi^{2} \\
\text { (Chi } \\
\text { Square) }\end{array}$} \\
\hline & Male & Female & & \\
\hline Average & 42 & 38 & 80 & \multirow{3}{*}{.573} \\
\hline High & 73 & 47 & 120 & \\
\hline Total & 115 & 85 & 200 & \\
\hline
\end{tabular}

From the above table it is found that the $\mathrm{p}$ value of Chi-square test is greater than 0.05 significance level which gradually support the null hypothesis and it can be said that on the basis of gender there is some amount of association but it is not strong enough to mention.

\begin{tabular}{|c|c|c|c|c|c|}
\hline $\begin{array}{c}\text { Degree of } \\
\text { Job }\end{array}$ & \multicolumn{3}{|c|}{ Age } & \multirow{2}{*}{ Total } & \multirow{2}{*}{$\begin{array}{c}\text { Value } \\
\text { of } \chi^{2} \\
\text { (Chi } \\
\text { Square) }\end{array}$} \\
\hline & $25-35$ & $36-45$ & $\begin{array}{l}46 \\
\text { and } \\
\text { above }\end{array}$ & & \\
\hline Average & 28 & 31 & 19 & 78 & \multirow{3}{*}{29.652} \\
\hline High & 62 & 33 & 25 & 120 & \\
\hline Total & 90 & 64 & 44 & 200 & \\
\hline
\end{tabular}

It is clear from the table that the value of Chi-square statistics is greater than the significance level, this shows that on the basis of age there is a significant and positive relation with the job performance. It is observed from table 5.24 that the percentage of respondents in the above 46 years age group among $(23.2 \%)$ the high job performance is comparatively lesser than two age categories.

\begin{tabular}{|c|c|c|c|c|c|c|}
\hline $\begin{array}{c}\text { Degree of } \\
\text { Job } \\
\text { Performanc }\end{array}$ & \multicolumn{4}{|c|}{ Education } & \multirow{2}{*}{ Total } & \multirow{2}{*}{$\begin{array}{c}\text { Value } \\
\text { of } \chi^{2} \\
\text { (Chi } \\
\text { Square) }\end{array}$} \\
\hline & $\begin{array}{c}10+ \\
2\end{array}$ & $\begin{array}{c}\text { Graduat } \\
\text { e }\end{array}$ & $\begin{array}{c}\text { Post } \\
\text { Graduat } \\
\text { e }\end{array}$ & $\begin{array}{c}\text { Professional } \\
\text { (According } \\
\text { to trade) }\end{array}$ & & \\
\hline Average & 26 & 29 & 34 & 14 & 103 & \multirow{3}{*}{29.652} \\
\hline High & 27 & 20 & 30 & 20 & 97 & \\
\hline Total & 53 & 49 & 64 & 34 & 200 & \\
\hline
\end{tabular}

\section{Work Related Factors- ANOVA Test}

At this level the researcher had tried to evaluate the variance in the responses of sampled employees with respect to E-HRM practices. The tested E-HRM practices are as follows:

- E-HRM changed the basic delivery of HR services

- E-HRM needs to consider the professional as strategic unit
- E-HRM claims for the learning of new skills

- E-HRM needs to change the responsibilities of line managers

- E-HRM calls for role reversal of concerned employees

ANOVA- Test Results

\begin{tabular}{|c|c|c|c|c|c|}
\hline & $\begin{array}{c}\text { Sum of } \\
\text { Squares }\end{array}$ & Df & Mean Square & F & Sig. \\
\hline
\end{tabular}




\section{E- HRM Practices in the IT Industry with Special Reference to the State of Karnataka}

\begin{tabular}{|c|c|c|c|c|c|c|}
\hline \multirow{3}{*}{$\begin{array}{l}\text { E-HRM changed the } \\
\text { basic delivery of HR } \\
\text { services }\end{array}$} & Between Groups & .094 & 1 & .094 & .051 & 0.002 \\
\hline & Within Groups & 925.634 & 498 & 1.859 & & \\
\hline & Total & 925.728 & 499 & & & \\
\hline \multirow{3}{*}{$\begin{array}{l}\text { E-HRM needs to } \\
\text { consider the } \\
\text { professional as } \\
\text { strategic unit }\end{array}$} & Between Groups & 3.992 & 1 & 3.992 & .737 & 0.254 \\
\hline & Within Groups & 532.030 & 498 & 1.068 & & \\
\hline & Total & 536.022 & 499 & & & \\
\hline \multirow{3}{*}{$\begin{array}{l}\text { E-HRM claims for the } \\
\text { learning of new skills }\end{array}$} & Between Groups & 4.297 & 1 & 4.297 & 3.412 & 0.065 \\
\hline & Within Groups & 627.245 & 498 & 1.260 & & \\
\hline & Total & 631.542 & 499 & & & \\
\hline \multirow{3}{*}{$\begin{array}{l}\text { E-HRM needs to } \\
\text { change the } \\
\text { responsibilities of line } \\
\text { managers }\end{array}$} & Between Groups & 7.539 & 1 & 7.539 & 6.003 & 0.015 \\
\hline & Within Groups & 625.389 & 498 & 1.256 & & \\
\hline & Total & 632.928 & 499 & & & \\
\hline \multirow{3}{*}{$\begin{array}{l}\text { E-HRM calls for role } \\
\text { reversal of concerned } \\
\text { employees }\end{array}$} & Between Groups & 2.581 & 1 & 2.581 & 1.588 & 0.908 \\
\hline & Within Groups & 809.387 & 498 & 1.625 & & \\
\hline & Total & 811.968 & 499 & & & \\
\hline \multirow{3}{*}{ Organization Flexibility } & Between Groups & 1.272 & 1 & 1.272 & 1.551 & 0.114 \\
\hline & Within Groups & 408.510 & 498 & .820 & & \\
\hline & Total & 409.782 & 499 & & & \\
\hline \multirow{3}{*}{$\begin{array}{c}\text { Observed } \\
\text { Discrimination }\end{array}$} & Between Groups & 2.207 & 1 & 2.207 & 2.952 & 0.086 \\
\hline & Within Groups & 372.343 & 498 & .748 & & \\
\hline & Total & 374.550 & 499 & & & \\
\hline
\end{tabular}

According to the above given ANOVA Table significant mean differences among area of work specialization were found with regard to the E-HRM practice dimensions Human resource management service delivery $(\mathrm{F}=.051, \mathrm{P}<0.05)$, $\mathrm{HR}$ professional as a strategic business partner $(\mathrm{F}=.737, \mathrm{P}<$ $0.05)$, New skills required for $\mathrm{HRM}(\mathrm{F}=3.412, \mathrm{P}<0.05)$ and Confidentiality, security \& e-HRM changing role requirement of $\mathrm{HR}$ professionals $(\mathrm{F}=6.003, \mathrm{P}<0.05)$. No significant mean differences were found with Human resource management responsibilities for line managers $(\mathrm{F}=$ $1.588, \mathrm{P}>0.05$ ). On comparing the respondents mean value of "Human resource management service delivery" across work specialization it was found that those who are working in account processing has the lowest $(\mathrm{M}=4.11)$ mean value in comparison with others. Comparing the mean value of respondents on the basis of "HR professional as a strategic business partner" revealed that those who are working in insurance specialization has the lowest $(M=4.25)$ mean value in comparison with others. 217 Mean value comparison of respondents on the basis of "New skills required for HRM" revealed that those who are working in account processing has the lowest $(\mathrm{M}=4.02)$ mean value in comparison with others On comparing the respondents mean value of "Human resource management service delivery" across work specialization it was found that those who are working in account processing has the lowest $(\mathrm{M}=4.11)$ mean value in comparison with others.

\section{CONCLUSION}

Findings show that the demographic profile of the respondents has positive impact on E-HRM Practices and job performance. Clustering of respondents has given us the way the job performance dimension as "High \& Average". High performance cluster support the organizational, social and psychological environment. Comparison of E-HRM Practices dimensions among the job performance groups have found that high \& average job performance cluster respondent differs in new skills required for key E-HRM Practices. It shows the cluster analysis is appropriate to have two cluster groups to do comparisons. High job performance clusters are given priority to make conclusions. Mediation effect plays an important role in finding the relationships between variables is given as effects on independent variables on dependent variable and mediator on dependent variables. In this research study, the hypothesis model indicates a positive effect on E-HRM Practices on Task, Contextual and Adaptive performance. 


\section{REFERENCES}

1. Rangarao, J. P., \& Raju, R. D. (2014, Jan 1). e-HRMadd value to the Human Resource Management - to obtain optimum potentials from the available Human Resources. Indian Journal of Commerce and management, 1(1).

2. Danialar, J. (2013). e-performance appraisal: Employee's perception as a determine out in fulfillment of the system. India: Wordpress

3. Noe, Hollenbeck, \& wright, G. a. (2003). Human Resource Management (4th ed.). New York: MacGraw-Hill Irwin.

4. Ulrich, D., \& Younger, J. (2008). The twenty first century human resource organization. Human Resource management, 73, 829-850.

5. Sitlani, Manish, Bhatia, N. k. (2012, April-June). Impact of working capital management practices of pharmaceutical firms on their profitability: An example of Ranbaxy Laboratories Ltd. Anvesha, the Journal of Management, 5(2), 18-24.

6. Shammy Shiri (2012). Strategic Role of HR Audit in Organizational Effectiveness,Manipal University, India Vol. 3, No. 2, June 2012

7. Davoudi, Seyed, \& Mousavi, M. (2012,May). Electronic human resource management: new avenues which leads to organizational success. A Journal of Multidisciplinary Research, 1(2). 